\title{
OS PERFIS TERRITORIAIS DO ALGARVE: ANÁLISE SOCIODEMOGRÁFICA
}

\author{
Renato Miguel do CARmo ${ }^{1}$
}

SoFIA SANTOS ${ }^{2}$

\begin{abstract}
Resumo - O texto analisa as mudanças sociodemográficas que ocorreram na região algarvia nas últimas duas décadas, contemplando dois objectivos: caracterizar e interpretar o sentido destas alterações e confrontar os resultados obtidos com os estudos mais recentes e com as visões clássicas que definem as divisões sub-regionais. Neste sentido, partimos das perspectivas mais clássicas para, seguidamente, apresentarmos uma análise de clusters para os momentos 1991 e 2001. Desta análise resultam quatro perfis territoriais, que são apresentados evidenciando duas tendências fundamentais: urbanização e marginalização. Particularizamos a observação no concelho de São Brás de Alportel que, apesar da localização interior, tem conhecido um dinamismo sociodemográfico pronunciado, permitindo o aprofundamento da análise e a discussão das tendências enunciadas.
\end{abstract}

Palavras-chave: Dinâmicas sociodemográficas, urbanização, marginalização, Algarve.

Abstract - The spatial profiles of the algarve: a sociodemographical ReAding. The paper draws upon sociodemographical changes of the last two decades in the Algarve region. Two main purposes are: to describe and interpret the meaning of these changes and to confront this analysis with recent studies and with the classical definitions of sub-regional areas. Using the classical perspectives as a starting point we then present the cluster analysis for 1991 and for 2001. Four territorial profiles are presented which reflect two main trends: urbanization and marginalization. Lastly, we focus on a specific municipality - São Brás de Alportel where strong sociodemographical dynamics have been identified despite its inland localization, enabling a more in-depth analysis and a discussion of the presented trends.

Keywords: Sociodemographical trends, urbanization, marginalization, Algarve.

Résumé - LES PROFILS TERRITORIAUX DE L'ALGARVE: UNE ANALYSE SOCIODÉMOGRAPHIQUE. On analyse les transformations sociodémographiques qui ont eu lieu en Algarve durant les deux dernières décennies, avec deux objectifs : caractériser et interpréter le sens de ces

Recebido: Setembro, 2009. Aceite: Junho, 2010.

1 Investigador auxiliar do Centro de Investigação e Estudos de Sociologia, do ISCTE - IUL. E-mail: renato.carmo@iscte.pt

2 Investigadora do Centro de Investigação e Estudos de Sociologia, do ISCTE - IUL.

E-mail: sofia.santos@iscte.pt 
changements et confronter les résultats obtenus avec les études les plus récentes et avec les visions classiques qui définissent les divisions subrégionales. En partant des perspectives les plus classiques, on présente ensuite une analyse de clusters pour les périodes 1991 et 2001. De cette analyse résultent quatre profils territoriaux, qui sont présentés en mettant en évidence deux tendances fondamentales : l'urbanisation et la marginalisation. L'observation de la municipalité (concelho) de São Brás de Alportel, qui a connu un dynamisme sociodémographique prononcé malgré sa localisation intérieure, permet d'approfondir l'analyse et la discussion des tendances énoncées.

Mots clés: Dynamiques sociodémographiques, urbanisation, marginalisation, Algarve.

\section{ALGARVE, UM 'PORTUGAL DEITADO'}

No seu livro sobre as regiões portuguesas, Jorge Gaspar (1993) recorre a duas metáforas bastante ilustrativas e sintomáticas, que definem em traços muito gerais a caracterização geográfica do Algarve. Segundo o autor, esta região assemelha-se a "um Portugal em ponto pequeno". Esta imagem sugerida "pela oposição entre um Portugal que se desenvolveu segundo a latitude e um Algarve em que a longitude é a dimensão maior, é a de que estamos perante um Portugal deitado". Logo no parágrafo seguinte, Jorge Gaspar clarifica os pressupostos que orientam a curiosa metáfora: "De facto, aqui encontramos 'rodando os eixos', as principais componentes do País, em formato reduzido: as duas unidades geológicas mais marcantes - Orla Sedimentar e Maciço Antigo; a oposição litoral-interior em termos de desenvolvimento socio-económico e de densidade demográfica; a bipolarização do sistema urbano Portimão-Faro versus Porto-Lisboa" (Gaspar, 1993: 178).

As distintas unidades geológicas pareciam acompanhar a separação entre diferentes espaços sociais, geográficos e paisagísticos. No interior uma extensa barreira montanhosa de orientação Este-Oeste (a serra de xisto); mais próxima do Atlântico emerge a serra de Monchique. Espraiando-se para sul uma vasta área de calcários constituída por montes e planaltos, que caracterizam a área do barrocal que, por sua vez, desagua no litoral.

Segundo Carminda Cavaco (1976), para além da composição geológica, era bem vincada a diferenciação entre formas de povoamento e de produção agrícola. Na serra, que conheceu na primeira metade do século XX a expansão do povoamento e do cultivo (designadamente, do trigo), fruto do desbravamento e das intensas arroteias levadas a cabo pelo trabalho das famílias camponesas, o tipo de povoamento dominante concentrava-se em pequenas povoações e aldeias. A este respeito Orlando Ribeiro referia: "o povoamento é recente e ainda ralo; não há lavouras que precisem de montes nem terra para grandes aldeias; apenas grupos de fogos, indício de uma colonização quase familiar que, partindo das baixas, progrediu ao longo dos barrancos" (Ribeiro, 1998: 161-162). Posteriormente, ao longo da segunda metade do mesmo século, a serra foi perdendo população e o mato voltou a tomar conta de parte substancial das terras, à semelhança do que sucedia até ao final do século XIX (Cavaco, 1976). A perspectiva da serra pouco povoada até meados do século XX não é perfilhada, porém, por todos os autores, nomeadamente, por Cristiana Bastos (1993).

O barrocal pode ser visto como uma área intermédia onde prosperam os pomares de árvores de sequeiro que identificam o cariz mediterrâneo da região (amendoeiras, alfarro- 
beiras, oliveiras, figueiras). O povoamento torna-se mais difuso, contrastando com o litoral, e tende a cobrir grande parte das encostas e cerros. Por sua vez, o Algarve litoral caracterizava-se por uma agricultura mais intensiva e de regadio e pela densificação do povoamento em vilas e cidades que, nas últimas quatro décadas, sofreram alguma industrialização e forte urbanização. Na verdade, a relação entre a localização litoral (com função portuária) e o crescimento urbano é um dos traços mais estruturantes da região. Recorrendo às observações de Orlando Ribeiro, "das oito maiores povoações algarvias (Lagos, Portimão, Silves, Loulé, Faro, Olhão, Tavira, Vila Real de Santo António), apenas Loulé não é ou não foi porto de mar ou de estuário; mesmo assim tinha, no fim da Idade Média, um porto onde exportava fruta e açúcar da sua horta" (Ribeiro, 1998: 163).

Para além desta divisão geográfica de sentido Norte-Sul, são conhecidas outras coordenadas para separar o Algarve ocidental, que liga o território ao oceano Atlântico (conhecido grosso modo como Barlavento), da zona oriental designada como Sotavento. As fronteiras territoriais desta e de outras divisões não são unânimes entre os diversos geógrafos (Monteiro, 1993). De qualquer modo, não é errado estabelecer que a "separação faz-se geralmente por Faro" (Ribeiro, 1998: 162). Para Jorge Gaspar, a centralidade geográfica e económico-administrativa de Faro, a capital de distrito, levou-o a identificar uma terceira área: o Algarve Central. Esta última secção territorial não é tão nítida como as anteriores, mas remete para uma centralidade que se reflecte em grande medida na dinâmica de urbanização ocorrida nas últimas décadas e que atinge vários concelhos circundantes - de Albufeira a Olhão, incluindo os mais interiores como Loulé e São Brás de Alportel, embora a inclusão de Olhão no Algarve Central não seja consensual (Carminda Cavaco, 1976).

No entanto, como iremos verificar, as dinâmicas de urbanização que despontam neste 'coração central' tendem a expandir-se para territórios diferenciados, que incluem cada vez mais os que se localizam na parte oriental da região. Por seu turno, na vertente ocidental destaca-se a urbanização quase contígua de duas cidades (Portimão e Lagos, com destaque para a primeira), cuja área forma um pólo urbano importante, embora de menor dimensão que o anterior. Como salienta Jorge Gaspar, "Portimão evidencia a vocação de porto comercial, a que vai juntar a de porto piscatório. O seu desenvolvimento marca uma tendência para a bipolarização urbana do Algarve" (Gaspar, 1993: 187).

De forma relativamente sintética podemos dizer que estes são os eixos essenciais a partir dos quais se tem caracterizado a situação geográfica do Algarve: o eixo vertical serra, barrocal, litoral; o eixo horizontal (ou transversal) - Algarve oriental, central e ocidental. No presente texto serão utilizados como um ponto referencial na identificação das dinâmicas sociodemográficas mais recentes que, de certa maneira, têm vindo a alterar algumas das perspectivas enunciadas.

A análise empreendida irá focar, num primeiro momento, o reforço da distinção entre os processos de urbanização, que se densificam e se intensificam nos concelhos litorais, face às dinâmicas regressivas, de despovoamento e de envelhecimento populacional, que caracterizam a maior parte das zonas do interior serrano. Esta configuração é visível numa primeira instância na distribuição da população ao nível da freguesia (fig. 1). Numa segunda parte, o estudo debruçar-se-á sobre o concelho de São Brás de Alportel que, apesar de se situar no interior reflecte um conjunto de transformações sociodemográficas pronunciadas. 


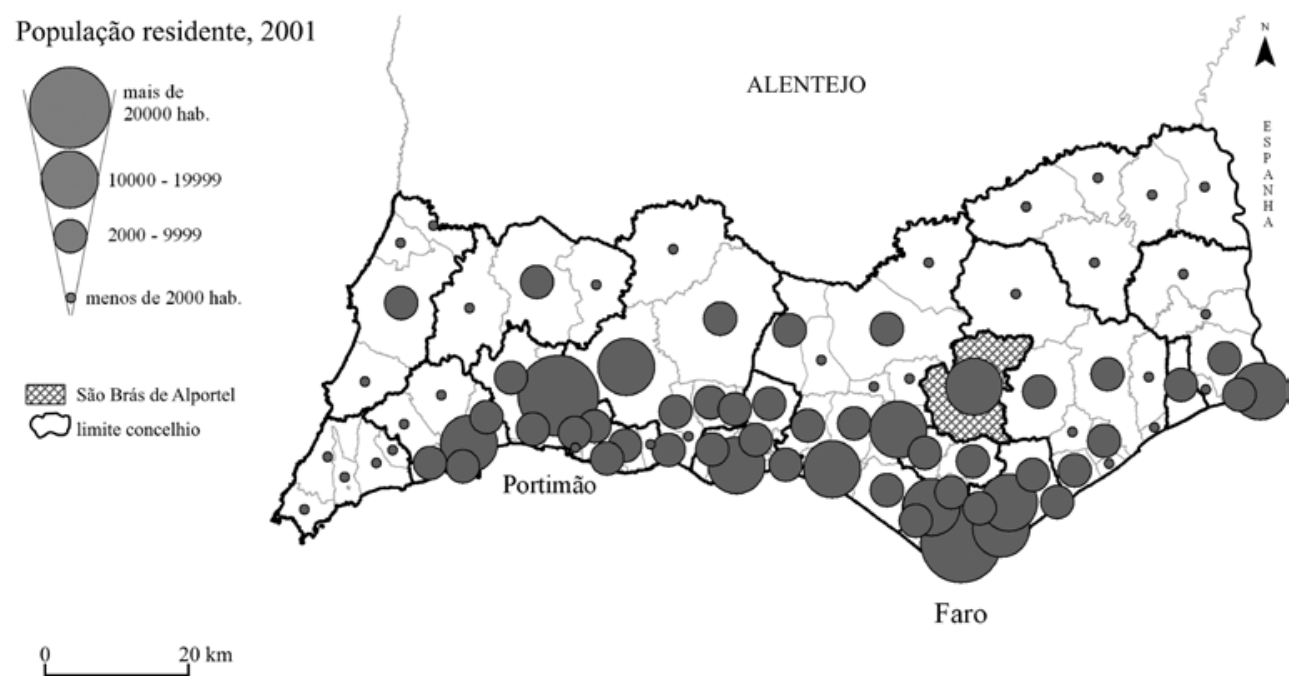

Fig. 1 - População residente em 2001 (Algarve) e localização do concelho de S. Brás de Alportel. Fig. 1 -Resident population in 2001 (Algarve) and in São Brás de Alportel.

Fonte: INE, 2001.

\section{PERFIS TERRITORIAIS DO ALGARVE}

Um estudo encomendado pelo NERA, Associação Empresarial da Região do Algarve (Guerreiro, 2008), retrata os traços gerais mais importantes da evolução da região algarvia nos últimos anos. Num dos capítulos deste estudo ensaia-se uma análise de clusters (à escala do concelho) que confirma o destaque de Faro e de Portimão enquanto pólos regionais onde há concentração de recursos, mais poder de compra, maior vitalidade económica, recursos humanos mais qualificados e maior dinâmica populacional. Em drástico contraste, surge um "interior despovoado" (Aljezur, Monchique, Alcoutim, e Castro Marim), em "cenário de 'morte social"' (Guerreiro, 2008: 17), risco de desertificação, carência de actividades económicas, serviços e infra-estruturas de apoio à população. Entre estes extremos surgem dois outros clusters: por um lado o Barlavento Litoral (Vila do Bispo, Lagos, Lagoa, Albufeira e Loulé), municípios urbanos caracterizados pela forte presença de população não residente, parque habitacional extenso, com volumetria elevada e níveis altos de conforto, e um mercado de trabalho dinâmico, por outro lado o Algarve Intermédio (Silves, São Brás de Alportel, Olhão, Tavira e Vila Real de Santo António) com um comportamento misto, integrando tendências do litoral urbanizado e do interior desertificado. Na realização desta análise foram utilizadas variáveis que caracterizam os diferentes níveis de desenvolvimento, de urbanização e de capacidade de atracção de população que persistem no Algarve. No entanto, a leitura ao nível do concelho pode não constituir a escala mais adequada, em particular numa região em que muitos destes atravessam as lógicas acima enunciadas.

Na procura da configuração de perfis territoriais do Algarve e da sua respectiva evolução, realizámos uma análise de clusters, como técnica exploratória. Utilizou-se como unidade de análise a freguesia e seleccionaram-se variáveis sociodemográficas que apontassem para as 
condições de habitabilidade, padrões de povoamento, níveis de escolarização e estrutura etária da população ${ }^{3}$. Através de um processo de selecção de variáveis mais robustas e significantes, demos ainda ênfase à evolução temporal, realizando a análise de clusters para dois momentos: 2001, integrando variáveis de variação 1991-2001, e 1991, integrando a variação 1981-19914. O facto de se apresentarem dados relativamente desactualizados, dada a distância que nos separa do último recenseamento, foi pesado face à valorização de uma escala mais adequada à realidade ao nível da escolha da unidade de análise. Se podemos actualizar alguns indicadores ao nível do concelho não deixamos no entanto de notar que, nalguns aspectos, a leitura dos perfis, ao nível da freguesia, estará mais próxima da realidade, ainda que distanciada temporalmente.

O objectivo central deste estudo é o de realizar uma análise em relação às dinâmicas internamente diferenciadas da região algarvia, no que respeita a um conjunto de indicadores sociodemográficos, tendo em conta as questões de escala acima referidas. Interessava sobretudo perceber como determinadas áreas do Algarve se têm comportado relativamente a variáveis-chave da dinâmica sociodemográfica e de evolução em termos de urbanização. Assim sendo, de modo a associar as variáveis à constituição dos grupos de freguesias, seguiu-se o método não hierárquico no agrupamento dos clusters, uma vez que estes métodos "destinam-se a agrupar sujeitos ou itens (e não variáveis) num conjunto de clusters cujo número é definido à partida" (Maroco, 2003: 321). O agrupamento foi realizado através do método não hierárquico (k-means) utilizando o software de estatística SPSS. No algoritmo usado são identificados, no início do processo, vários centróides ou centros de cluster, tendo-se recorrido previamente ao agrupamento hierárquico como meio de sugestão do número de grupos a definir. O processo começa com um conjunto inicial de $\mathrm{k}$ médias, sendo os casos classificados com base na distância euclidiana relativamente a essas médias, passando por um processo de iteração (cálculo sucessivo das médias e da pertença de cada caso aos diferentes perfis face às novas médias) com vista a optimizar a pertença de cada caso a um dos k clusters.

Daqui resultaram, numa primeira instância, três grupos para cada momento (2001 e 1991). Dois grupos são claramente distintos e opostos: de um lado as freguesias representativas das dinâmicas de urbanização e do outro as que contemplam factores agravados de marginalização. O terceiro cluster é intermédio em termos de composição sociodemográfica, integrando um conjunto de freguesias com características menos vincadas. Numa análise mais fina, decompôs-se este último em dois subgrupos distintos utilizando, para o efeito, a taxa de variação da população, de modo a separar as freguesias que apresentam tendências regressivas das que obtêm algum crescimento populacional. Assim sendo, ficamos com qua-

3 População residente $\left(\mathrm{n}^{\circ}\right)$, Taxa de variação da população (\%), Índice de envelhecimento (\%), População 0-14 anos (\%), População 15-24 anos (\%), População 25-64 anos (\%), População com mais de 65 anos (\%), Taxa de variação da população 0-14 anos (\%), Taxa de variação da população 15-24 anos (\%), Taxa de variação da população 25-64 anos (\%), Taxa de variação da população com 65 ou mais anos (\%), Taxa de analfabetismo (\%), População residente com ensino superior completo (\%), Taxa de actividade (\%), Edifícios $\left(n^{\circ}\right)$, Alojamentos por edifício $\left(n^{\circ}\right)$, Taxa de variação dos edifícios (\%), Alojamentos sem pelo menos uma infra-estrutura básica (\%), População que reside em lugares com mais de 2000 habitantes (\%).

4 De 1981 a 2001 o número e a dimensão das freguesias algarvias foi-se alterando. Para a realização da análise de clusters para 1991 foram utilizadas as freguesias existentes em 1981, para estabelecer uma análise comparativa, já que se utilizavam taxas de variação 81-91. O mesmo não acontece para 2001, uma vez que o INE disponibiliza os dados de 1991 já com as freguesias existentes em 2001. Por isso, foram estas as utilizadas para a constituição dos clusters neste caso. Contudo, foi tida em conta esta questão em termos analíticos e de interpretação da evolução da constituição dos grupos. 
tro perfis territoriais distintos: uma área em processo consolidado de urbanização, outra caracterizada por factores de marginalização e duas áreas com posição intermédia - uma em crescimento e outra em regressão demográfica.

A definição de cada cluster não se altera muito entre 1991 e 2001 ao nível das variáveis que o caracterizam. Contudo, como veremos posteriormente, a respectiva configuração territorial sofre alterações assinaláveis. Ainda assim, de 1991 para 2001, as variáveis relacionadas com a composição etária da população tendem a ganhar poder discriminante, apesar de as variáveis "proporção de população a viver em lugares com mais de 2000 habitantes" e "taxa de analfabetismo" tenderem a perder alguma importância. Contudo, em ambos os momentos o "índice de envelhecimento" e a "taxa de analfabetismo" são das variáveis mais discriminantes, tal como as condições de habitabilidade em termos de infra-estruturas das habitações. Vejamos agora a caracterização geral destes clusters nos dois momentos escolhidos (fig. 2 e 3 ).

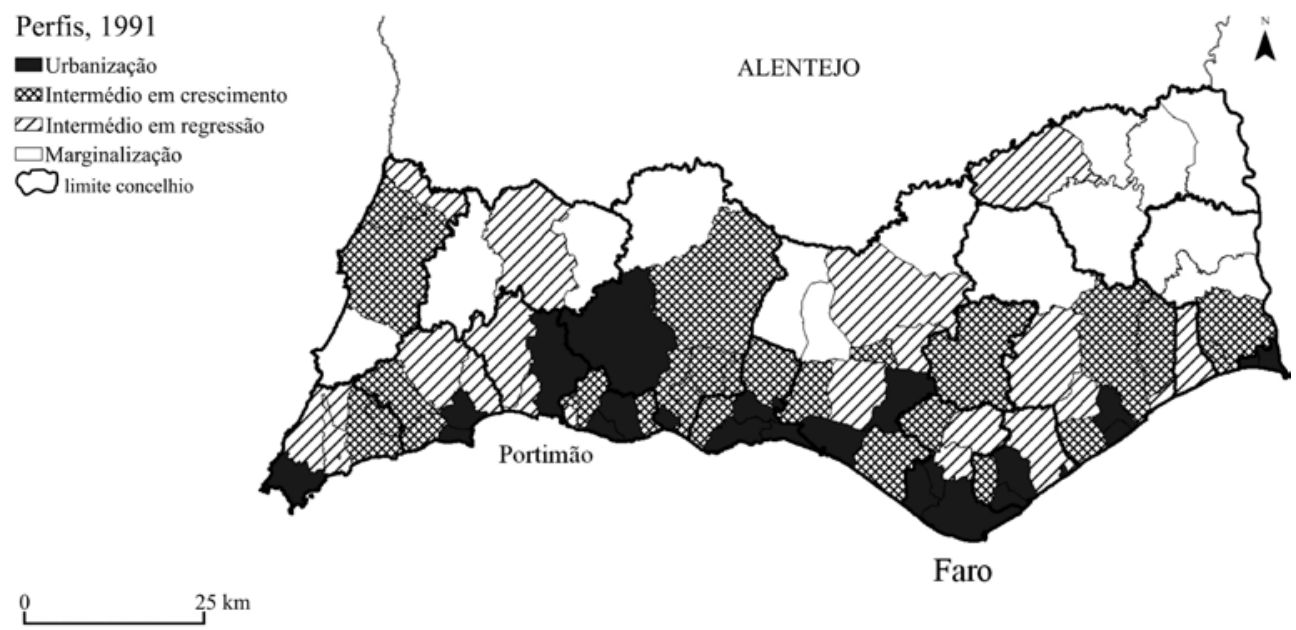

Fig. 2 - Perfis sociodemográficos da região do Algarve, 1991. (ver texto para esclarecimento da legenda)

Fig. 2 - The Algarve's sociodemographical profiles for 1991. (see text for clarification)

As freguesias em urbanização caracterizam-se obviamente pela dimensão populacional: maior volume e concentração populacional (elevada percentagem de população residente em lugares com mais de 2000 habitantes), mais população activa e instruída (baixa taxa de analfabetismo e elevada percentagem de população com ensino superior completo). Também o edificado urbano existe em maior quantidade e densidade, registando um maior número de alojamentos por edifício e apresenta, globalmente, melhores infra-estruturas (menor quantidade de alojamentos sem pelo menos uma infra-estrutura básica). É ainda uma área que demonstra não só níveis de urbanização mais elevados mas também uma dinâmica de crescimento forte na última década, apresentando taxas de variação da população, total e em todos os grupos etários, mais elevadas, o mesmo acontecendo para a taxa de variação dos edifícios. Trata-se das freguesias mais urbanas e das sedes de concelho destacando-se a centralidade de Lagos, Portimão, Albufeira, Loulé/Quarteira, Faro, Olhão, Tavira e Vila Real de Santo António. 
Em 2001 já não contamos neste cluster com Silves, Sagres e Fuseta. Esta última, porque perdeu território para a freguesia de Moncarapacho; as primeiras duas devido a dinâmicas de regressão mais à frente analisadas. Em paralelo, há o reforço das centralidades de Faro, expandindo-se em ligação com Olhão, Loulé e São Brás de Alportel, mas também de Albufeira. Neste grupo não podemos deixar de destacar o aumento populacional, por um lado, das freguesias de Ferreiras e de Olhos de Água e por outro, de São Brás de Alportel que irrompe para Norte, na direcção da serra, a progressão do cluster em urbanização.

O cluster em marginalização encontra-se claramente marcado pelas lógicas da desertificação populacional e de envelhecimento. São freguesias com um índice de envelhecimento elevado, depauperadas em termos populacionais, em particular ao nível da população em idade activa, e em perda acentuada na última década, com taxas de variação negativas. A população residente apresenta níveis mais elevados de analfabetismo e uma percentagem muito reduzida de pessoas com o ensino superior completo. Neste grupo não há população a residir em lugares com mais de 2000 habitantes. O cluster corresponde à serra algarvia que, de 1991 para 2001, parece continuar a acentuar o seu processo de marginalização.

Em 2001 constituem este cluster todo o concelho de Alcoutim, as freguesias serranas de Loulé, de Tavira e de Castro Marim, para além do concelho de Monchique (excepção feita à freguesia sede de concelho) e outras freguesias de Aljezur (Bordeira) e Silves (São Marcos da Serra). Relativamente a Alcoutim, um dos três concelhos algarvios sem ligação ao litoral (com Monchique e São Brás de Alportel), destaca-se o facto de nem a sede de concelho escapar à marginalização. Neste sentido, a leitura ao nível de freguesia torna-se quase indispensável numa região como o Algarve em que os valores médios concelhios escondem variações determinantes no comportamento regional.

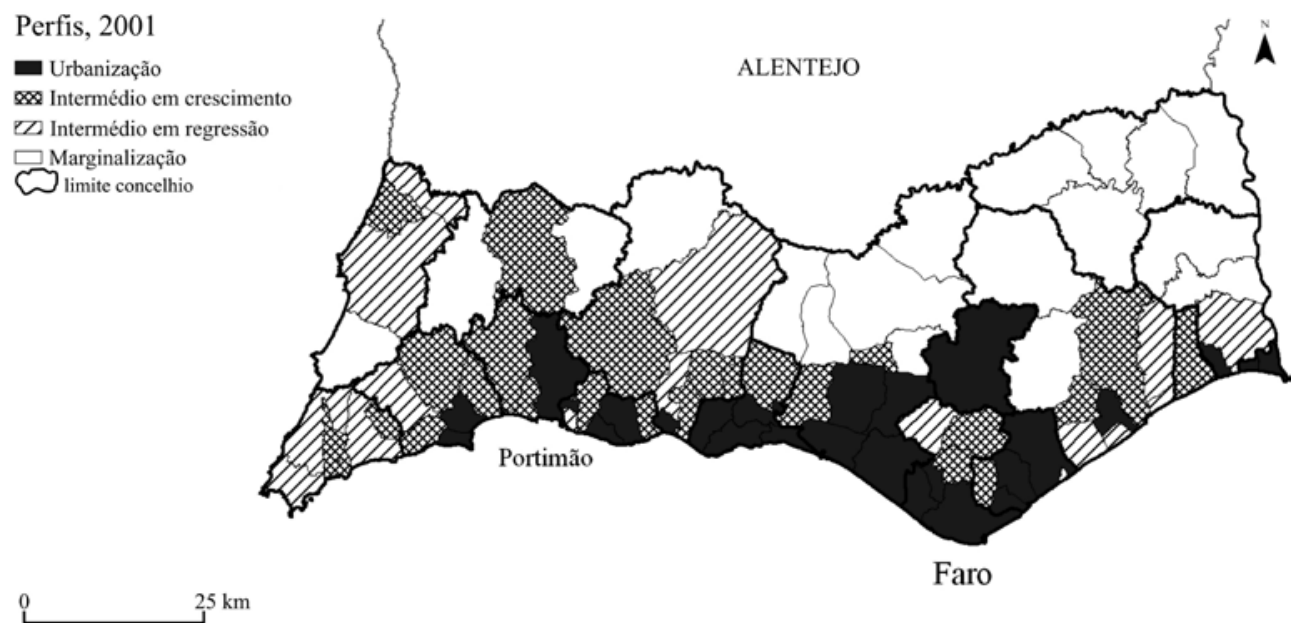

Fig. 3 - Perfis sociodemográficos da região do Algarve, 2001. (ver texto para esclarecimento da legenda)

Fig. 3 - The Algarve's sociodemographical profiles for 2001. (see text for clarification). 
O cluster intermédio (em regressão ou em crescimento) reúne o maior número de freguesias e exibe comportamentos mais próximos ora da lógica da urbanização ora da marginalização. No entanto, relativamente à sua evolução, embora apresente, de uma forma geral, valores mais próximos da média, as taxas de variação da população (total e por grupos etários) comportam-se positivamente na constituição do cluster para 1991, enquanto para 2001 apresenta valores negativos, ainda que não muito elevados. Isto é, o perfil dos dois subgrupos intermédios aproximava-se mais, em 1991, do perfil de urbanização no que diz respeito à dinâmica de crescimento populacional - apresentando aliás um valor negativo nos centróides apenas para a taxa de variação da população com mais de 65 anos - enquanto em 2001 os centróides referentes a todas as taxas de variação do cluster intermédio se comportavam negativamente.

A evolução do grupo intermédio revela duas configurações territoriais. Por um lado, observamos alguma regressão no lado ocidental, na medida em que freguesias como Sagres ou Silves perdem algum dinamismo (em 1991 ocupavam o cluster de maior urbanização). Outras freguesias, dos concelhos de Aljezur e Vila do Bispo, que apresentavam uma dinâmica de crescimento de 1981 para 1991, denotam na década seguinte uma tendência de regressão. Por outro lado, agrava-se a situação sociodemográfica do nordeste algarvio, no qual desaparece quase por completo o perfil intermédio, seja de crescimento ou de regressão, quase desaparecendo uma área de transição entre urbanização e marginalização.

A análise da configuração geográfica dos clusters completa-se com a leitura da respectiva composição ao nível da população (quadro I).

Quadro I - Evolução dos quatro perfis territoriais, em número de freguesias e de população residente.

Table I-The evolution of four territorial profiles defined by the number of parishes and population.

\begin{tabular}{|c|c|c|c|c|c|c|c|c|c|}
\hline \multirow[b]{3}{*}{ Perfis } & \multicolumn{4}{|c|}{1991} & \multicolumn{4}{|c|}{2001} & \multirow{3}{*}{$\begin{array}{c}\text { 1991-2001 } \\
\text { Variação } \\
\text { população }\end{array}$} \\
\hline & \multicolumn{2}{|c|}{ Freg. } & \multicolumn{2}{|c|}{ População } & \multicolumn{2}{|c|}{ Freg. } & \multicolumn{2}{|c|}{ População } & \\
\hline & $\mathrm{n}^{\mathrm{o}}$ & $\%$ & $\mathrm{n}^{\mathrm{o}}$ & $\%$ & $\mathrm{n}^{\mathrm{o}}$ & $\%$ & $\mathrm{n}^{\mathrm{o}}$ & $\%$ & \\
\hline Área em urbanização & 23 & 27,4 & 191511 & 56,1 & 26 & 31,0 & 258438 & 65,4 & 34,9 \\
\hline Área em crescimento & 27 & 32,1 & 82016 & 24,0 & 24 & 28,6 & 77990 & 19,7 & $-4,9$ \\
\hline Área em regressão & 20 & 23,8 & 52312 & 15,3 & 16 & 20,2 & 38925 & 9,8 & $-25,6$ \\
\hline Área em marginalização & 14 & 16,7 & 15565 & 4,6 & 18 & 20,2 & 19865 & 5,0 & 27,6 \\
\hline Total & 84 & 100 & 341404 & 100 & 84 & 100 & 395218 & 100 & 15,8 \\
\hline
\end{tabular}

Fonte: elaboração própria com base em INE - Recenseamento Geral da População e da Habitação (RGPH), 1991 e 2001.

A leitura destes dados permite-nos sugerir que a evolução mais determinante e visível no Algarve é a expansão da urbanização. As áreas em urbanização aumentaram o volume populacional em cerca de $35 \%$, passando quase dois terços da população algarvia a residir nestas freguesias. Contudo, outros dados relevantes emergem destes números: observa-se uma perda de importância das situações intermédias de urbanização e, conse-

5 Calculada considerando o valor total de cada perfil, tomando o grupo como unidade. 
quentemente, verifica-se o crescimento da área sinalizada por graves problemas de depressão demográfica. As principais tendências enunciadas confirmam-se pela observação das médias das taxas de variação da população, total e por grupos etários, das freguesias que compõem cada grupo em 2001 (quadro II). A observação por grupos etários é especialmente ilustrativa da diferenciação dos perfis: o de urbanização apresenta taxas de variação sempre positivas; o de crescimento revela uma evolução positiva no total e na população em idade activa, mas também na população idosa, ainda que negativa nos grupos mais jovens; no perfil de regressão verificam-se taxas de variação negativas particularmente fortes nos grupos mais jovens e positivas para a população com mais de 65 anos; o de marginalização é marcado pela perda transversal e acentuada de população, particularmente grave na população até aos 15 anos.

Quadro II - Taxas médias de variação da população por perfil sociodemográfico (2001), total e por grupos etários.

Table II - Average variation ratios of resident population by: socio-demographic profile (2001), total and by age group.

\begin{tabular}{lcccc}
\cline { 2 - 5 } & \multicolumn{4}{c}{ Perfis 2001 } \\
\hline Taxas de variação da população & Urbanização & Crescimento & Regressão & Marginalização \\
\hline População total & 25,2 & 9,9 & $-8,9$ & $-24,4$ \\
População 0-14 anos & 14,0 & $-8,1$ & $-28,5$ & $-43,5$ \\
População 15-24 anos & 27,0 & $-0,9$ & $-16,7$ & $-28,6$ \\
População 25-64 anos & 46,9 & 17,9 & $-3,3$ & $-22,5$ \\
População com 65 ou mais anos & 46,8 & 25,3 & 7,8 & $-0,4$ \\
\hline
\end{tabular}

Fonte: elaboração própria com base em INE - RGPH, 1991 e 2001.

\section{AS NOVAS VISÕES DO TERRITÓRIO ALGARVIO}

Os mapas apresentados (fig. 2 e 3) resumem as tendências identificadas pela análise anterior. É notória a expansão do perfil de urbanização por territórios que, em 1991, se caracterizavam pela sua composição intermédia. Tendo por base as divisões geográficas descritas na secção inicial, verificamos que parte destas freguesias se situa na zona do barrocal. Na verdade, se em 1991 ainda existia alguma correspondência entre a situação geográfica do barrocal (localizado entre a serra e o litoral) e a sua composição sociodemográfica intermédia, observa-se, para 2001, uma alteração considerável, consubstanciada na penetração da urbanização em direcção a certas freguesias mais interiores.

Este processo é particularmente visível nos concelhos que circundam o designado Algarve Central, cujo epicentro se situa na cidade de Faro. Ou seja, reforça-se a centralidade da área urbana da capital de distrito, que se expande tanto para zonas litorais contíguas (desde Albufeira, a Oeste, até Tavira, a Leste), como para territórios que se estendem até à serra (com particular destaque para São Brás de Alportel). Tendo em conta estas dinâmicas,

6 Calculada considerando o valor total de cada perfil, tomando o grupo como unidade. 
identifica-se uma certa agudização da assimetria entre as áreas de urbanização e as zonas que padecem de níveis crescentes de marginalização. Não é descabido dizer que a posição intermédia do barrocal se vai esvaziando, ao mesmo tempo que se fortalecem os factores de maior polarização territorial.

Esta dinâmica não afecta com a mesma intensidade o Algarve ocidental. De facto, verificamos que a área de urbanização polarizada pelo eixo Portimão-Lagos perdeu algum fulgor expresso, nomeadamente, na alteração do perfil de Silves, que em 1991 compunha o cluster das freguesias mais urbanizadas e, em 2001, surge associada ao grupo identificado pelas dinâmicas intermédias de crescimento. Ou seja, parece que a tradicional bipolarização entre as áreas urbanas de Faro e de Portimão se tornou ela própria mais desigual a favor da primeira embora, Faro e Portimão continuem a destacar-se quanto ao nível de urbanização do restante Algarve. Sem se caminhar para um sistema unipolar, é inegável o reforço de urbanização a partir do 'coração central' da região.

Sintetizando, ao longo da década de 90 depreende-se uma alteração significativa da configuração geográfica do Algarve. Se em 1991 ainda era possível esboçar um paralelismo entre a composição dos clusters e a divisão do Algarve em litoral, serra e barrocal, em 2001 este padrão parece desfazer-se devido, fundamentalmente, ao quase desaparecimento da posição intermédia do barrocal. Confirma-se então o acentuar da diferenciação litoral / interior e o reforço claro da polaridade de Faro, que se espraia às freguesias e concelhos circundantes. Por outro lado, o dito Algarve Ocidental tende a perder importância, ainda que Portimão continue a destacar-se, em conjunto com Faro, como um centro urbano da maior importância.

Para além destas tendências gerais observa-se simultaneamente uma reconfiguração do sistema de urbanização da região, que deixa de se circunscrever às zonas do litoral. Em certos casos, a urbanização tende a 'galgar' pelo interior adentro e a atingir áreas que até há pouco tempo se encontravam relativamente imunes a estes processos.

É interessante perceber em que medida esta nova configuração da geografia algarvia é comprovada por outras análises, designadamente as que foram produzidas no âmbito do Plano Regional de Ordenamento do Território do Algarve (PROTAL). Este documento desenha um modelo territorial para a região algarvia que se pretende que resulte da caracterização e diagnóstico da região (com especial ênfase no estudo de ocupação do solo e do sistema urbano) e que também ilustre as opções estratégicas consideradas na proposta de planeamento.

"A região do Algarve organiza-se hoje em quatro espaços territoriais bem distintos, que não resultam apenas das suas características biofísicas, edafo-climáticas e socio-económicas, mas que são também resultado das transformações estruturais operadas na região ao longo das últimas décadas em função do enorme desenvolvimento das actividades turísticas e do relativo declínio das actividades económicas tradicionais anteriores. Estes quatro espaços territoriais coincidem também com as quatros unidades de paisagem da região.” (PROTAL, 2004 - Caracterização e Diagnóstico, Anexo O - Ocupação Urbanística, p.48).

São quatro as unidades identificadas pelo documento, a saber: o Litoral Sul e Barrocal, a Serra, o Baixo Guadiana e a Costa Vicentina. No quadro (quadro III) sistematizamos as principais características de cada unidade proposta pelo PROTAL.

É interessante observar as alterações veiculadas pela perspectiva do PROTAL face a outros estudos sobre a região, como é o caso da Estratégia de Desenvolvimento do Algarve para o período 2000-2006 (CCDR-Algarve, 2000). Este documento, também de 
planeamento, definia igualmente quatro subsistemas: o Litoral (entre Lagos e Tavira), o subsistema Costa Vicentina, o subsistema Guadiana (que integrava o núcleo urbano de Vila Real de Santo António) e o subsistema Serra/Barrocal (abrangia uma área de transição entre a serra despovoada e o litoral, com características predominantemente rurais). Mais recentemente, a estratégia 2007 - 2013 (CCDR; 2006) já vai buscar assumidamente como base a leitura territorial e a análise que se estava a elaborar no âmbito do PROTAL em 2004.

Comparando os dois primeiros documentos referidos, destacam-se duas alterações mais pronunciadas: na divisão territorial proposta pelo PROTAL o núcleo urbano de Vila Real de Santo António deixa de fazer parte do subsistema Guadiana para integrar o litoral e, mais determinante, o barrocal deixa de estar associado ao subsistema serrano para passar a estar mais ligado ao litoral. Isto é, evidenciou-se o processo de polarização territorial entre o reforço da urbanização, que tende a expandir-se pelo barrocal adentro, e a regressão contínua que afecta parte substancial do interior algarvio.

Quadro III - Síntese da caracterização das unidades territoriais do Algarve.

Table III - Summary the description of Algarve's territorial units.

\begin{tabular}{|c|c|}
\hline Litoral Sul e Barrocal & $\begin{array}{l}\text { De Lagos a Vila Real de Santo António (VRSA), esta unidade resulta do alargamento } \\
\text { do conceito de litoral ao espaço do barrocal. Esbate-se a diferenciação em termos de } \\
\text { ocupação do solo destas duas unidades e observa-se a convergência de vários problemas } \\
\text { e conflitualidades que advém do tipo de ocupação humana. É aqui que se concentra a } \\
\text { larga maioria da população, das actividades económicas e dos alojamentos e } \\
\text { equipamentos. }\end{array}$ \\
\hline Serra & $\begin{array}{l}\text { Desde a Costa Vicentina ao Baixo Guadiana, temos o centro-interior do Algarve. Esta } \\
\text { unidade territorial caracteriza-se pelo fraco dinamismo económico, pela rarefacção do } \\
\text { povoamento e pela forte presença de actividades pecuárias e florestais. }\end{array}$ \\
\hline Baixo Guadiana & $\begin{array}{l}\text { Constituída por partes dos concelhos de Vila Real de Santo António, Castro Marim, } \\
\text { Tavira e Alcoutim. Esta unidade existe em função de uma identidade construída em } \\
\text { torno do Rio Guadiana e da fisiografia da bacia hidrográfica, caracterizando-se pela } \\
\text { desertificação física e humana e uma quase inexistente base económica e produtiva. }\end{array}$ \\
\hline Costa Vicentina & $\begin{array}{l}\text { Inclui a maior parte dos concelhos de Aljezur e Vila do Bispo, exibindo uma paisagem } \\
\text { costeira bem particular. Povoamento pouco intenso, em pequenos núcleos rurais e } \\
\text { elevado valor cénico e ecológico associado também a um enquadramento histórico- } \\
\text {-cultural. Caracteriza-se por um fraco dinamismo económico e insuficientes } \\
\text { acessibilidades. Pretende-se potenciar a ligações destes dois concelhos com Lagos como } \\
\text { eixo de desenvolvimento de um 'triângulo vicentino'. }\end{array}$ \\
\hline
\end{tabular}

Fonte: Adaptado de PROTAL, 2007.

Em sobreposição com esta visão surge um sistema urbano mais complexo que, segundo o PROTAL, se organiza a partir de um conjunto diferenciado de centralidades:

- Faro-Loulé-Olhão, com ligações a São Brás de Alportel e Quarteira/Vilamoura e Almancil.

- Portimão-Lagos-Lagoa, com ligações a Silves.

- Albufeira-Guia, em articulação com as duas centralidades anteriores.

- Vila Real de Santo António-Castro Marim, com ligações a Andaluzia.

- Tavira, fazendo a interligação entre Vila Real de Santo António - Castro Marim e Faro. 
Um dos objectivos deste documento estratégico é o de transformar esta espécie de arquipélago urbano (Ferrão, 2002; Carmo, 2008), constituído por diferentes nódulos, numa proposta de sistema policêntrico, através do incremento das interacções e complementaridades estabelecidas entre várias áreas urbanas. A este propósito pode ter a máxima importância aquilo que o documento apresenta como os pontos de ligação entre as centralidades apresentadas e os eixos de articulação que são assim identificados pelo PROTAL: o eixo de articulação central (Albufeira, Guia), o eixo de articulação interior/litoral (Silves, Loulé, São Brás de Alportel), do Triângulo Vicentino (Aljezur, Vila do Bispo, Sagres, Lagos) e o eixo de articulação transversal serrano (Alcoutim, Pereiro, Martim Longo, Cachopo, Salir, Benafim, Alte, S. Bartolomeu de Messines, S. Marcos da Serra, Alferce, Monchique, Marmelete, Aljezur). São Brás de Alportel, Loulé e Silves são os três concelhos que estão presentes nas centralidades identificadas, funcionando ainda como eixos de articulação. A sua posição geográfica confere-lhes especial importância na relação entre o Algarve urbano e o Algarve serrano.

Considerando os traços essenciais do PROTAL, deparamo-nos com algumas similitudes relativamente à análise de clusters que realizámos e que poderíamos resumir tendo por base dois fenómenos marcantes: a polarização territorial e a complexificação do sistema urbano. Ambos marcam a geografia da região e remetem necessariamente para escalas de análise diferenciadas. A polarização não é obviamente uma tendência recente na região, pois já desde os anos 1970 o Algarve apresenta esta tendência, temporal e espacial, dado o grande desenvolvimento turístico do litoral algarvio (Moreno, 2001). Esta leitura vem, contudo, confirmar a extensão para Norte e para Este da litoralização em termos de urbanização: o barrocal junta-se ao litoral e juntos abarcam ainda Vila Real de Santo António - antes pertencente ao subsistema do Guadiana. Vila do Bispo e toda a costa vicentina persistem, todavia, num subsistema relativamente marginalizado, não se detectando através dos dados sociodemográficos, distinção assinalável entre as freguesias serranas dos subsistemas Serra e Baixo Guadiana, embora esta separação seja feita pelo PROTAL. No entanto, reconhece-se e sublinha-se a diversidade do interior algarvio (Moreno, 2001). Na verdade, se a partir de uma perspectiva mais abrangente é inegável o incremento da oposição litoral/interior e da consequente polarização territorial, isso não retira de cena outras dinâmicas mais finas que só podem ser contempladas a nível local.

\section{O CASO DE SÃO BRÁS DE ALPORTEL}

São Brás de Alportel é um concelho completamente interior e um dos três concelhos apontados anteriormente como integrando, simultaneamente, aglomerações urbanas e eixos de articulação. Localizado numa faixa de transição entre o barrocal e a serra, São Brás de Alportel foi tomado na última década pela lógica de urbanização, usufruindo do crescimento do sistema Faro-Loulé-Olhão.

O crescimento demográfico do concelho dá-se claramente na década 1991-2001 e parece continuar (quadro IV). Esta década representou um período de crescimento considerável para a região algarvia, com vários concelhos detendo taxas de variação da população superiores a $15 \%$, quando o valor nacional foi de $5 \%$, e quatro concelhos a ultrapassar os $20 \%$. São Brás de Alportel foi, neste período, dos poucos que continuou a dinâmica de crescimento em níveis bastante assinaláveis, se comparado com os concelhos circundantes, como Loulé e Faro, ou mesmo com concelhos que haviam tido dinâmica semelhante para o período 1991-2001, mas que abrandaram este processo de 2001 a 2008, como Vila Real de Santo António. 
Em sede própria fez-se já o correcto diagnóstico da evolução demográfica deste concelho. No Diagnóstico Social do Concelho de São Brás de Alportel (CLASSBA, 2006) identificam-se as tendências e sugerem-se causas ou mecanismos que têm levado ao que é considerado como a dimensão estruturante das dinâmicas locais: o crescimento demográfico. Foi aliás o concelho que mais cresceu de 2001 a 2008, ultrapassando o valor de Albufeira (quadro IV).

Quadro IV - Taxas de variação da população na região algarvia, por concelho, 1981-2008.

Table IV - Variation ratios of the resident population in the Algarve region, by municipality, 1981-2008.

\begin{tabular}{lrrr}
\hline \multicolumn{1}{c}{ Unidade territorial } & $1981-1991$ & $1991-2001$ & 2001-2008 \\
\hline Portugal & 0,3 & 5,0 & 2,6 \\
Algarve & 5,5 & 15,8 & 8,8 \\
Albufeira & 21,7 & 50,6 & 23,5 \\
Alcoutim & $-13,1$ & $-17,5$ & $-17,7$ \\
Aljezur & $-1,0$ & 5,6 & 0,7 \\
Castro Marim & $-6,8$ & $-3,1$ & $-1,8$ \\
Faro & 12,5 & 14,4 & 1,1 \\
Lagoa & 7,3 & 23,1 & 20,5 \\
Lagos & 9,3 & 18,0 & 13,7 \\
Loulé & 5,8 & 27,0 & 10,6 \\
Monchique & $-23,9$ & $-4,6$ & $-13,6$ \\
Olhão & 6,5 & 10,9 & 8,6 \\
Portimão & 12,7 & 15,4 & 11,3 \\
S. Brás de Alportel & 0,3 & 33,3 & 25,3 \\
Silves & 4,9 & 2,8 & 6,9 \\
Tavira & 1,0 & 0,6 & 1,6 \\
Vila do Bispo & 1,1 & $-7,2$ & 1,3 \\
V. Real de S.to António & $-11,9$ & 24,7 & 3,2 \\
\hline
\end{tabular}

Fonte: INE - RGPH 1981, 1991, 2001; INE - Anuário Estatístico da Região do Algarve (AERA), 2009.

O Diagnóstico Social do Concelho de São Brás de Alportel (2006) avança como factores explicativos deste crescimento demográfico a oferta da habitação a preços mais competitivos, face a concelhos vizinhos (como Loulé e Faro), a qualidade ambiental do concelho e a melhoria das acessibilidades. No entanto, a atracção de população residente não tem correspondência na oferta de emprego, como assinala o dito relatório. De entre as freguesias que constituem o cluster mais urbanizado, a freguesia de São Brás de Alportel é a terceira que apresenta maior percentagem de pessoas que trabalha, ou estuda, fora do município $(35,9 \%)$, em 2001 (INE - RGPH 2001). Esta observação é pertinente, se atendermos à situação particular de São Brás de Alportel, enquanto concelho de uma só freguesia, o que significa que em termos de concentração de serviços e respectiva capacidade de empregabilidade poderia oferecer mais oportunidades. 
Observando as taxas de variação de população por grupos etários (quadro V), em cada concelho algarvio, São Brás de Alportel apresenta a mais elevada taxa de variação de população entre os 25 e os 65 anos, de 2001 para 2008: este grupo etário cresceu mais de $50 \%$, enquanto a média regional ronda os $24 \%$. Confirma-se a atractividade do concelho para a população residente em idade activa, apesar da limitada capacidade de oferta de emprego.

Quadro V - Taxas de variação da população concelhia 2001-2008, por grupos etários. Table V-Variation ratios of resident population in Algarve municipalities, 2001-2008, by age groups.

\begin{tabular}{lrrrr}
\hline & \multicolumn{4}{c}{ Faixas etárias } \\
\hline \multicolumn{1}{c}{ Unidade territorial } & \multicolumn{1}{c}{$0-14$} & $15-24$ & $25-65$ & $>65$ \\
\hline Portugal & $-1,2$ & $-18,8$ & 14,2 & 11,6 \\
Algarve & 16,2 & $-9,6$ & 24,5 & 12,5 \\
Albufeira & 12,4 & 13,6 & 47,4 & 27,2 \\
Alcoutim & $-31,8$ & $-42,5$ & 2,5 & $-15,1$ \\
Aljezur & 0,3 & $-4,9$ & 22,3 & $-0,7$ \\
Castro Marim & $-3,9$ & $-22,3$ & 15,7 & $-1,2$ \\
Faro & 14,3 & $-23,0$ & 12,4 & 12,0 \\
Lagoa & 16,1 & 3,6 & 40,6 & 24,0 \\
Lagos & 13,4 & 2,5 & 32,7 & 15,6 \\
Loulé & 24,0 & $-3,9$ & 26,7 & 12,2 \\
Monchique & $-31,0$ & $-26,8$ & 3,4 & $-1,5$ \\
Olhão & 30,8 & $-13,2$ & 15,5 & 20,8 \\
Portimão & 42,8 & $-11,9$ & 22,1 & 19,9 \\
S. Brás de Alportel & 15,8 & 13,5 & 53,3 & 32,4 \\
Silves & 6,4 & $-12,0$ & 27,0 & 2,7 \\
Tavira & 0,3 & $-20,2$ & 21,2 & 1,4 \\
Vila do Bispo & $-9,3$ & $-10,2$ & 21,1 & 2,2 \\
V. Real de S.to António & $-3,6$ & $-16,5$ & 19,8 & 15,6 \\
\hline
\end{tabular}

Fonte: INE - AERA, 2009.

Em termos globais, a comparação com Faro e Loulé pode sugerir uma tendência de consolidação da expansão para Norte da aglomeração urbana do Algarve Central. Os dados relativos a este município apresentam valores um pouco surpreendentes para um concelho interior do Algarve inserindo-o no perfil mais urbanizado, como se verificou no ponto anterior. Para além do crescimento demográfico, São Brás de Alportel apresentava, em 2001, indicadores de escolarização muito idênticos ao nível nacional, sendo mesmo ligeiramente mais elevados que o nível regional: a taxa de analfabetismo era 9,3\% (Portugal: 9,0\%; Algarve: $10,4 \%$ ) e a proporção de população com ensino superior completo 7,5\% (Portugal: 8,6\%; Algarve: 7,3\%). Apesar da tendência de rejuvenescimento identificada, o envelhecimento da população é, ainda assim, superior à média nacional e regional 
(quadro VI), estando muito longe, contudo, dos níveis alarmantes dos concelhos mais interiores (Alcoutim: 532,4\%; Monchique: 327,3\%). A dinâmica de urbanização é sobretudo visível ao nível do aumento populacional e do povoamento, parecendo manter-se até à actualidade (quadro VI).

Quadro VI - Indicadores demográficos 2001 e 2008 - S. Brás de Alportel, Algarve e Portugal. Table VI-Demographic indicators for 2001 and 2008 - for S. Brás de Alportel, Algarve and Portugal.

\begin{tabular}{lrrrr}
\hline \multicolumn{1}{c}{ Indicadores } & Ano & Portugal & Algarve & $\begin{array}{c}\text { S. Brás } \\
\text { Alportel }\end{array}$ \\
\hline \multirow{2}{*}{ População residente $\left(\mathrm{n}^{\mathrm{o}}\right)$} & 2008 & 10627250 & 430084 & 12569 \\
& 2001 & 10356117 & 395218 & 10032 \\
\multirow{2}{*}{ Densidade populacional $\left(\mathrm{n}^{\circ} / \mathrm{km}^{2}\right)$} & 2008 & 115,4 & 86,1 & 82,0 \\
& 2001 & 112,3 & 78,3 & 67,0 \\
Índice de envelhecimento (\%) & 2008 & 115,5 & 123,5 & 160,8 \\
& 2001 & 104,2 & 128,4 & 156,3 \\
Pop. resid. em lugares com 2000 ou mais habitantes (\%) & 2008 & 53,5 & 44,3 & 30,8 \\
& 2001 & 54,8 & 48,2 & 38,5 \\
\hline
\end{tabular}

Fonte: INE - RGPH 2001; INE - AERA, 2009.

Não estamos, contudo, a falar de tecidos urbanos contínuos, mas de ligações entre centralidades de dimensão variável, com interstícios de ocupação agrícola ou pequenos núcleos rurais, tal como assinala a leitura da ocupação do solo produzida pelo PROTAL (2007). Por outro lado, apesar de haver uma grande concentração de população na vila de São Brás de Alportel e em emergentes zonas residenciais, parte do território continua a apresentar características claramente mais próximas da realidade serrana. Observando as dinâmicas internas no concelho de São Brás de Alportel, apercebemo-nos desta variabilidade e da reprodução interna da tendência de polarização.

Para a construção do quadro VI recorremos à desagregação à secção, aglutinando posteriormente as secções respeitantes a cada unidade geográfica apresentada. A junção foi feita com base na observação local do território e no Plano de Urbanização da Vila de São Brás de Alportel. Outro aspecto que determinou a construção destas unidades, tendo em conta a capacidade de produção de dados comparativos, foi a alteração do número e configuração geográfica das secções de 1991 para 2001. O crescimento demográfico do concelho de 1991 para 2001 (fig. 4) deve-se essencialmente à vila (67\%) e a novas áreas residenciais em áreas relativamente próximas da vila e de eixos viários, enquanto a serra apresenta perda de população (em cerca de 10\%), apesar do valor elevado do concelho (33\%).

Afinando a leitura confirmamos o envelhecimento crescente na serra e a persistente rarefacção do povoamento (quadro VII). Em 2001, 41\% da população tinha mais de 65 anos, quase mais $10 \%$ do que em 1991 e mais cerca $20 \%$ do que é verificado no restante território; a densidade populacional era de cerca de 5 pessoas por $\mathrm{km}^{2}$, face aos $1417 \mathrm{hab} / \mathrm{km}^{2}$ da vila, um valor que na serra se altera pouco, com uma trajectória descendente de 1991 para 2001, 
aumentando, pelo contrário, nas outras unidades. Por outro lado, também o perfil da população ao nível da qualificação demonstra a dupla lógica urbanização/marginalização acima demonstrada para os clusters da região: concentração da população com ensino superior na vila e persistência de valores elevados de analfabetismo na serra. Aqui não será demais realçar também a dimensão crescente de 1991 para 2001 da população residente na vila que tem ensino superior.

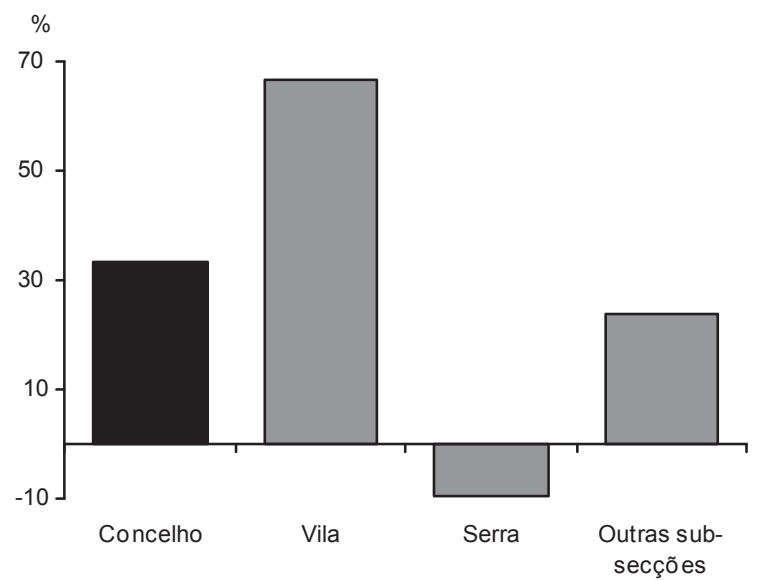

Fig. 4 - Taxas de variação da população 1991 - 2001 no concelho de São Brás de Alportel. Fig. 4 - Variation ratios of resident population from 1991 to 2001 for the São Brás de Alportel municipality.

Fonte: INE - RGPH, 1991 e 2001.

Quadro VII - Indicadores estatísticos de S. Brás de Alportel, 1991 e 2001.

Table VII - São Brás de Alportel statistical indicators for 1991 and 2001.

\begin{tabular}{|c|c|c|c|c|c|c|c|c|}
\hline \multirow[b]{2}{*}{ Indicadores } & \multicolumn{2}{|c|}{ Concelho } & \multicolumn{2}{|c|}{ Vila } & \multicolumn{2}{|c|}{ Serra } & \multicolumn{2}{|c|}{ Outras secções } \\
\hline & 1991 & 2001 & 1991 & 2001 & 1991 & 2001 & 1991 & 2001 \\
\hline População residente $\left(\mathrm{n}^{\circ}\right)$ & 7526 & 10032 & 1939 & 3232 & 369 & 334 & 5218 & 6466 \\
\hline Densidade populacional $\left(\mathrm{hab} / \mathrm{km}^{2}\right)$ & 50,2 & 66,8 & 893,5 & 1417,5 & 4,7 & 4,2 & 76,3 & 94,5 \\
\hline População residente 0-19 anos (\%) & 22,8 & 19,7 & 25,2 & 21,7 & 16,3 & 12,3 & 22,4 & 19,1 \\
\hline População residente 20-64 anos (\%) & 55,3 & 58,2 & 58,4 & 61,0 & 51,5 & 46,4 & 54,4 & 57,5 \\
\hline Pop. residente com mais de 65 anos (\%) & 21,9 & 22,0 & 16,4 & 17,2 & 32,2 & 41,3 & 23,2 & 23,4 \\
\hline Residentes que não sabem ler nem escrever (\%) & 15,0 & 15,0 & 9,2 & 10,9 & 37,7 & 36,5 & 15,6 & 15,9 \\
\hline Residentes com curso superior completo (\%) & 1,3 & 5,9 & 2,1 & 7,4 & 0,0 & 0,9 & 1,2 & 5,5 \\
\hline Total de alojamentos $\left(\mathrm{n}^{\circ}\right)$ & 3789 & 5420 & 1080 & 1732 & 146 & 203 & 2563 & 3485 \\
\hline Total de edifícios $\left(\mathrm{n}^{\circ}\right)$ & 3242 & 4272 & 687 & 935 & 143 & 203 & 2412 & 3134 \\
\hline Alojamentos por edifício $\left(\mathrm{n}^{\circ}\right)$ & 1,2 & 1,3 & 1,6 & 1,9 & 1,0 & 1,0 & 1,1 & 1,1 \\
\hline Área $\left(\mathrm{km}^{2}\right)$ & 150 & 150,1 & 2,2 & 2,3 & 79,4 & 79,4 & 68,4 & 68,4 \\
\hline
\end{tabular}

Fonte: INE - RGPH, 1991 e 2001. 
De um modo geral, confirma-se a dupla lógica na evolução da população empregada (fig. 5): de 1991 para 2001 a população empregada do concelho cresce $57,2 \%$, sendo este valor de $92,1 \%$ na vila e de $46 \%$ nas outras secções, tendo decrescido $14,7 \%$ na serra (RGPH, 2001 e 1991). A evolução por sector de actividade demonstra o declínio do sector agrícola no concelho, mantendo-se, ainda assim, uma diferença assinalável, em 2001, entre a população empregada no sector primário na serra $(20 \%)$ e na vila $(2 \%)$.

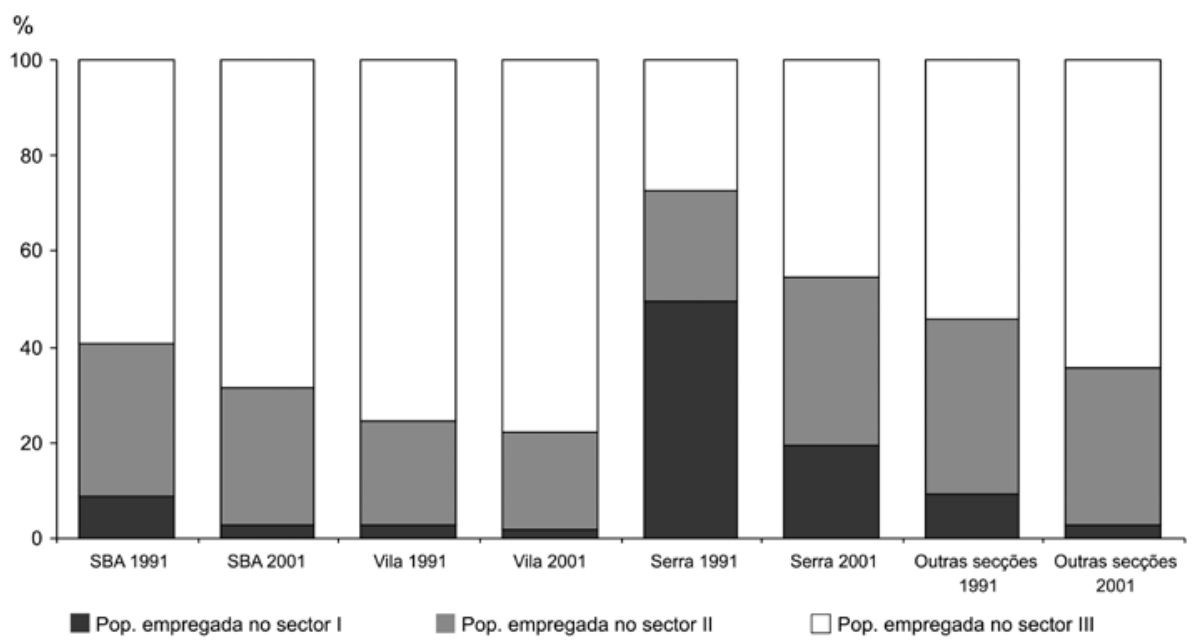

Fig. 5 - População empregada por sector de actividade, em áreas de S. Brás de Alportel, 1991 e 2001. Fig. 5 - Employed population by economic sector, in the areas of São Brás de Alportel, for 1991 and 2001.

Fonte: INE - RGPH, 1991 e 2001.

Em paralelo, também o parque edificado apresenta obviamente dimensões muito variáveis, consoante a unidade geográfica, embora o alojamento unifamiliar seja muito frequente em todo o concelho. Contudo, o diagnóstico social do concelho chama a atenção para a dinâmica do mercado imobiliário também na zona da serra. Em entrevistas realizadas a construtores há menção da venda de tipologia T3, nomeadamente a estrangeiros oriundos da Europa do Norte. Esses construtores descrevem ainda outro perfil de procura: "casais jovens, à procura da primeira habitação que vêem no concelho a oportunidade de encontrarem habitações mais espaçosas a preços mais baixos que os praticados noutros concelhos (...), jovens que têm emprego nos concelhos limítrofes." (CLASSBA, 2006: 25). O próprio diagnóstico destaca o risco avançado de São Brás de Alportel passar a ser "vila dormitório".

Este risco, tido como uma ameaça no relatório, não deixa de aparecer, contudo, como um dos possíveis factores explicativos do crescimento demográfico do concelho - a atractividade residencial para população activa empregada em concelhos circundantes - e assim também da inclusão de São Brás de Alportel na lógica de urbanização. 


\section{CONCLUSÃO}

Este texto pretendeu actualizar algumas das perspectivas geográficas sobre o Algarve, partindo das divisões regionais que tradicionalmente são utilizadas para caracterizar a composição física e demográfica da região. Quer pela análise de clusters realizada, quer por referência a outros estudos que se debruçaram sobre este território, podemos concluir que elas sofreram uma alteração significativa. Na verdade, um dos traços mais salientes da leitura feita refere-se à intensificação da distinção entre a faixa litoral e a serra, que se expressa na expansão da urbanização pela área intermédia do barrocal. Certas zonas localizadas mais para o interior encontravam-se imunes aos processos de densificação urbana, que desde meados dos anos 60 do século passado invadiram o litoral, conheceram entretanto uma profunda dinamização expressa, entre outros aspectos, no aumento considerável da população residente.

O caso de São Brás de Alportel é paradigmático a este respeito. Trata-se de um concelho interior que tem vindo a crescer exponencialmente. Esta evolução deve-se, em grande parte, à relativa proximidade geográfica da cidade de Faro e à melhoria das vias de comunicação que ligam a vila à capital de distrito. Embora não tenhamos dados que o comprovem plenamente, podemos sugerir que São Brás se integra, nalguns aspectos, num processo de suburbanização, já que parte substancial da população activa exerce actividade profissional no exterior (com destaque para Faro). Por sua vez, a parte serrana do concelho continua a sofrer uma contínua regressão demográfica que dificilmente poderá ser invertida.

Tendo em conta as dinâmicas gerais da região e aquelas que detectámos para São Brás de Alportel, observa-se, por um lado, uma dualidade estrutural, cada vez mais pronunciada, entre as áreas de urbanização localizadas no litoral (e parcialmente no barrocal) e as zonas de montanha que caminham para a marginalização inevitável, e, por outro lado, uma complexificação do sistema de urbanização que tende a diversificar as centralidades territoriais e as respectivas relações de complementaridade funcional. Novos focos de dinamismo emergem no Algarve que gradualmente vão redireccionando a sua organização espacial.

\section{AGRADECIMENTO}

Agradecemos as questões e as sugestões dos referees da Finisterra, que em muito enriqueceram este trabalho.

Texto elaborado no âmbito do projecto "Associações voluntárias e desenvolvimento local: políticas públicas, capital social e cidadania" (referência: PTDC/SDE/69882/2006) financiado pela Fundação para a Ciência e a Tecnologia. O relatório produzido no âmbito deste projecto foi recentemente publicado em livro (Carmo, 2011).

\section{BIBLIOGRAFIA}

Bastos C (1993) Os montes do Nordeste Algarvio. Cosmos, Lisboa.

Carmo R M (2011) Entre as cidades e a serra: mobilidades, capital social e associativismo no interior algarvio. Editora Mundos Sociais, Lisboa.
Carmo R M (2008) Portugal, sociedade dualista em questão: dinâmicas territoriais e desigualdades sociais. In da Silva F C, Wall K, Cabral M $\mathrm{V}$, Aboim S (eds.) Itinerários. A investigação nos 25 Anos do ICS. Imprensa de Ciências Sociais, Lisboa: 373-394. 
Cavaco C (1976) O Algarve Oriental: as vilas, o campo, o mar. Gabinete do Planeamento da Região do Algarve, Faro.

Conselho Local de Acção Social de São Brás de Alportel (CLASSBA) (2006) Diagnóstico social do concelho de São Brás de Alportel. http:// www.cm-sbras.pt/portal_autarquico/sao_ bras_alportel/v_pt-pt/menu_municipe/servicos_municipais/accao_social/rede_social [Acedido a 22 de Junho de 2009]

Ferrão J (2002) Portugal, três geografias em recombinação. Lusotopie, 2: 151-158.

Gaspar J (1993) As regiões portuguesas. Ministério do Planeamento e da Administração do Território, Lisboa.

Guerreiro J (coord.) (2008) Caracterização da estrutura económica do Algarve. NERA. http:// www.nera.pt/HomePage/Default.asp [Acedido a 22 de Junho de 2009]

MAOTDR, CCDRAlg (2007) Plano Regional de Ordenamento do Território - PROT Algarve, Vol I - Plano. http://www.territorioalgarve.pt/Storage/pdfs/Volume_I.pdf [Acedido a 22 de Junho de 2009]

MAOTDR, CCDRAlg (2006) Estratégia de Desenvolvimento do Algarve 2007-2013. http://www. ccdr-alg.pt/ccdr/parameters/ccdralg/files/File/ documentos/ Estrategia_Algarve_2007-13.pdf [Acedido a 22 de Junho de 2009]

MAOTDR, CCDRAlg (2004) Plano Regional de Ordenamento do Território - PROT Algarve. Vol II - Caracterização e Diagnóstico, Anexo
O-Ocupação Urbanistica. http://www.territorioalgarve.pt/Storage/pdfs/Volume_II_ ANEXO_O.pdf [Acedido a 22 de Junho de 2009]

MAOTDR, CCDRAlg (2000) Estratégia de desenvolvimento para a região do Algarve 2000 2006. Comissão de Coordenação e Desenvolvimento Regional do Algarve. http://www. ccdr-alg.pt/ccdr/parameters/ccdr-alg/files/ File/documentos/estrategia.pdf [Acedido a 22 de Junho de 2009]

Maroco J (2003) Análise estatística - Com utilização do SPSS. Edições Sílabo, Lisboa.

Monteiro P (1993) Sítios de querença. Morfologias e processos sociais no Alto Barrocal Algarvio. Dissertação de Doutoramento, Instituto Superior de Ciências do Trabalho e da Empresa, Lisboa.

Moreno L (2001) The deep rural context and micro-regional changes in Southern Portugal. In Jussila M, Delgado-Cravidão (ed.) Globalization and Marginality in Geographical Space, Ashgate: 121-134.

Ribeiro O (1998) Portugal, o Mediterrâneo e o Atlântico. Livraria Sá da Costa, Lisboa.

\section{Informação estatística}

INE (2009) Anuário Estatístico da Região do Algarve 2008. Lisboa.

INE (1981, 1991, 2001) Recenseamento Geral da População e da Habitação. Lisboa. 